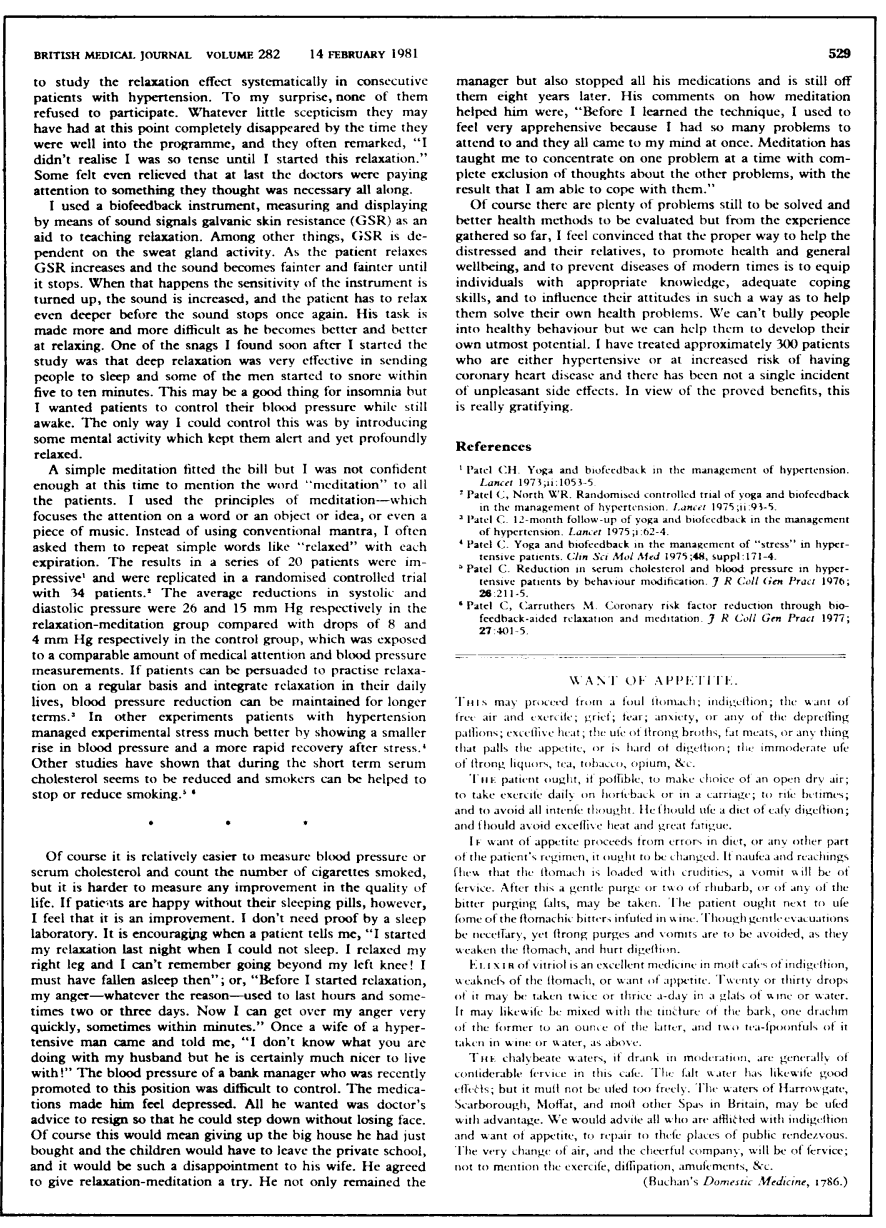

soo

\section{Emergencies in the Home}

\section{Electrocution, drowning, and burns}

A FRASER-DARLING
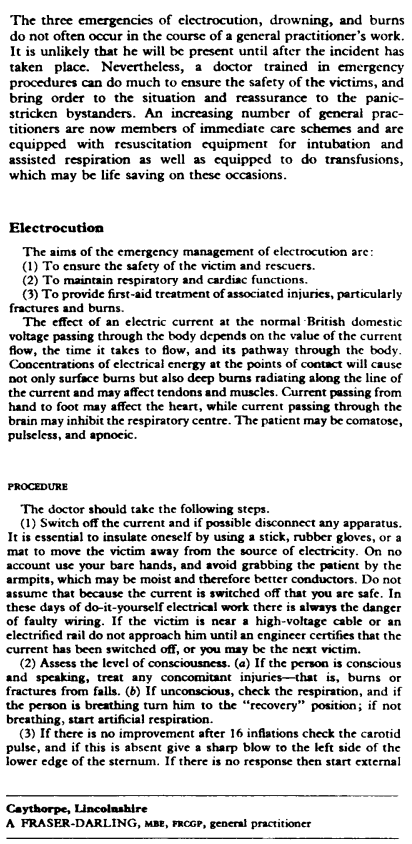
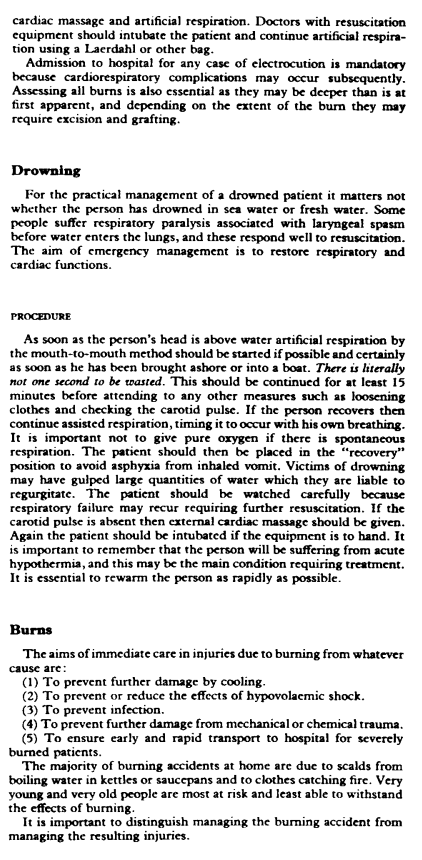

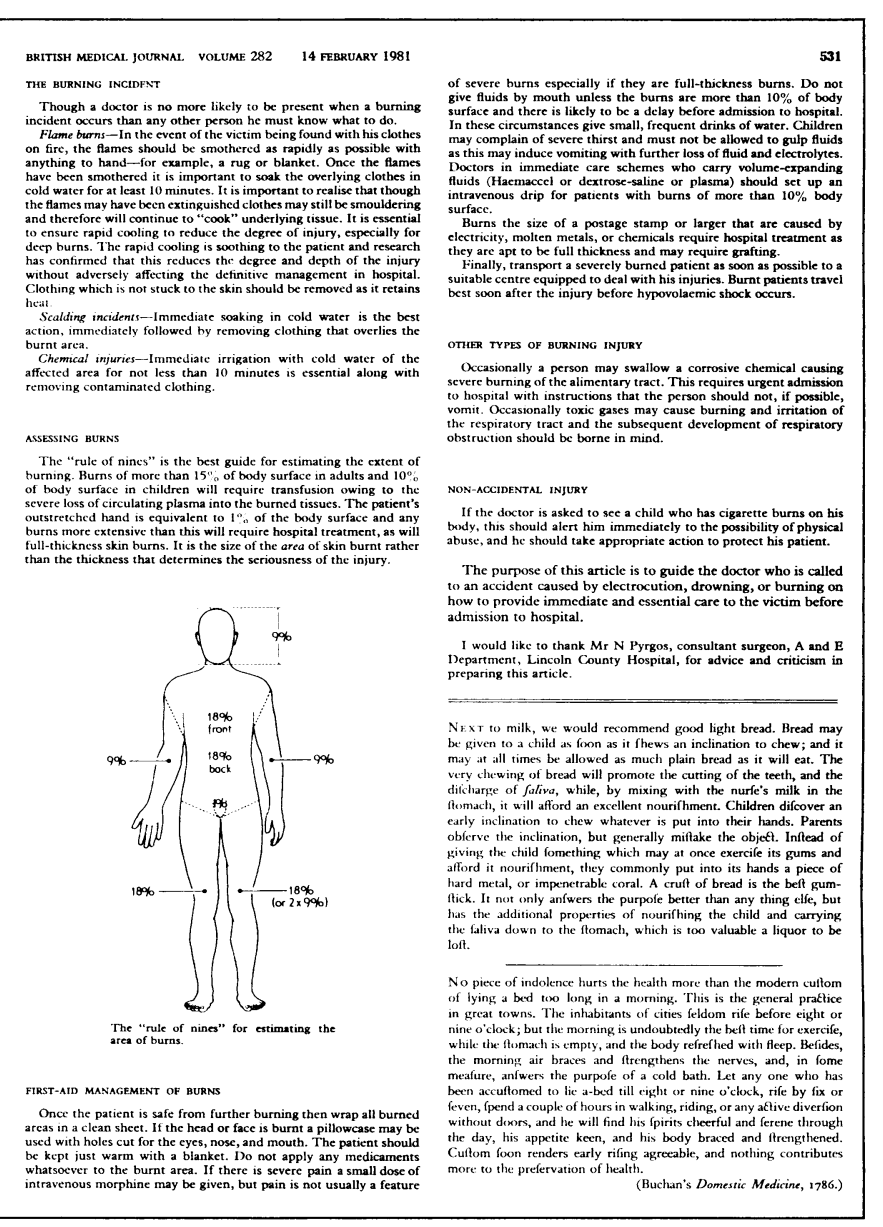

532

BRITISH MEDICAL JOURNAL VOLUME $282 \quad 14$ FEBRUARY 1981

\section{Pitfalls in Practice}

\section{Finding a practice}

IV: What a contract should include

JOHN OLDROYD

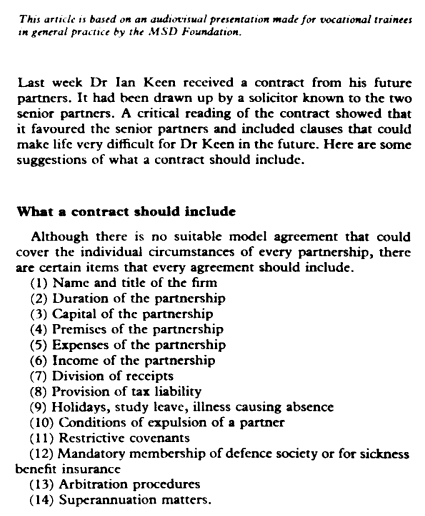

INCOME

What is a reasonable income for an incoming partner to
expect? ? No hard and fast rule can to laid down. Circumstances

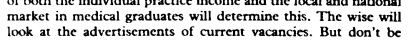
misted by high gross sncomes sadvertised. Net incomes will be reduced by the practice expenses, and this is often a very
different figure. Equally, parity will be largely dependent on the markect and local circumstances.
It is usual to consider all reccipts as the property of the

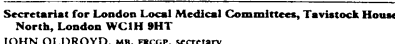

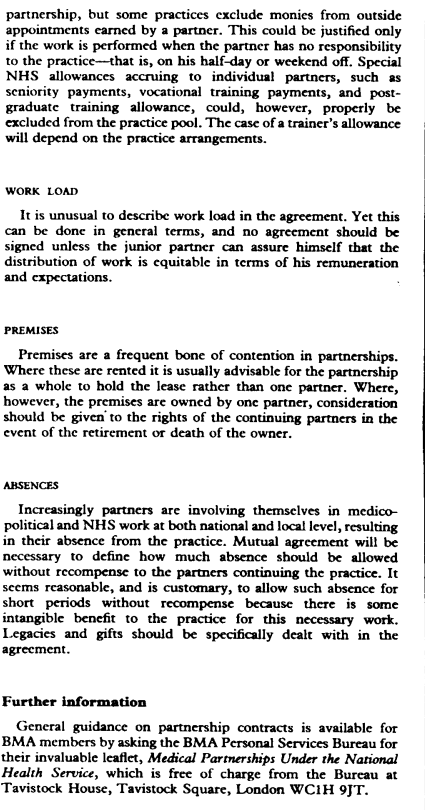

